\title{
Avaliação reológica e tecnológica de farinhas de trigo integrais
}

\author{
Andressa de Souza Fratari (IC), Georgia Ane Raquel Sehn (PG), Caroline Joy Steel (PQ)
}

\section{Resumo}

O objetivo deste trabalho foi avaliar o comportamento reológico e tecnológico de diferentes farinhas de trigo integrais $(\mathrm{FTI})$. As $\mathrm{FTI}$ apresentaram maior absorção de água, tempo de desenvolvimento, índice de tolerância à mistura, resistência à extensão, e menor estabilidade e extensibilidade. Além de baixos volumes específicos. Concluiu-se que as FTI apresentam uma grande variedade na sua composição, principalmente no teor de fibra, o que interfere nas características reológicas e tecnológicas dos pães de forma.

Palavras Chave: pães integrais, farinógrafo, extensógrafo

\section{Introdução}

No Brasil, a farinha de trigo integral consiste na reincorporação da fração de farelo à farinha de trigo refinada. Além disso, os testes reológicos realizados com a farinha de trigo auxiliam a indústria de panificação a predizer as características de processamento da massa e a qualidade dos produtos finais.

O objetivo deste trabalho foi avaliar a composição centesimal, a granulometria, e o comportamento reológico e tecnológico de 11 diferentes farinhas de trigo integrais, e uma farinha de trigo refinada como controle (formulação 12) através das análises de farinografia (absorção de água, tempo de chegada, tempo de desenvolvimento da massa, estabilidade, tempo de saída e índice de tolerância à mistura) e extensografia (resistência à extensão, extensibilidade, resistência máxima, número proporcional e energia) das massas e o volume específico dos pães de forma.

\section{Resultados e Discussão}

Observou-se que, os pães com farinha integral apresentaram maior teor de proteínas, fibras e cinzas em relação ao controle com farinha de trigo refinada. As amostras com maiores teores de fibra alimentar e características granulométricas mais grossas apresentaram menores volumes específicos. De maneira geral, as amostras integrais apresentaram maior absorção de água, maior tempo de desenvolvimento da massa, menor estabilidade e menor tolerância à mistura (maior ITM); maior resistência à extensão, menor extensibilidade e maior número proporcional, alguns destes parâmetros característicos de uma farinha forte, segundo os padrões utilizados atualmente para farinha de trigo refinada, entretanto o reflexo destes resultados não foi confirmado no volume específico dos pães. As amostras integrais apresentaram baixos volumes específicos (Figura 1).

\section{Conclusões}

Com este trabalho, podemos concluir que as farinhas de trigo integrais comerciais apresentam uma grande variedade na sua composição, principalmente no teor de fibra, o que interfere de maneira significativa nas características reológicas das massas e nas características tecnológicas dos pães. Devido à falta de legislação específica para farinhas e produtos integrais não foi possível estabelecer uma relação entre os resultados das análises reológicas com o volume especifico dos pães de forma.
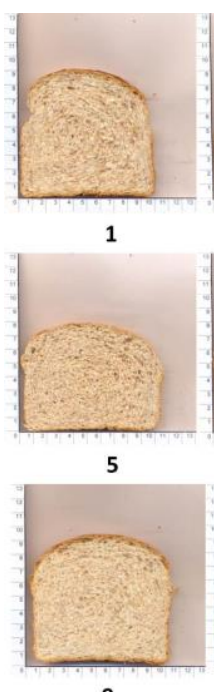

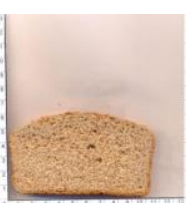

2

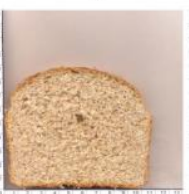

6

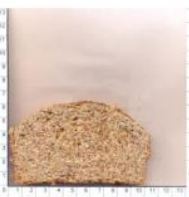

10

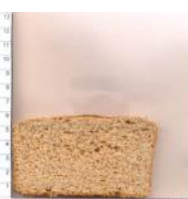

3
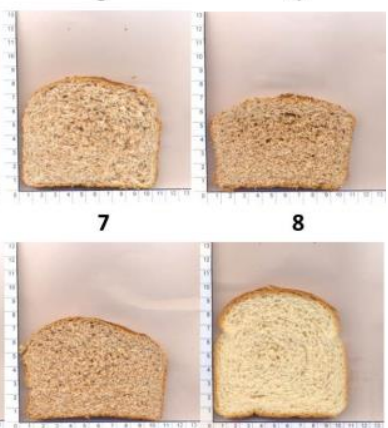

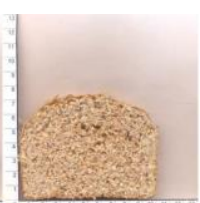

Figura 1. Imagens das fatias centrais dos pães de forma (Formulações 1 a 12).

Agradecimentos

Gostaria de agradecer ao SAE/UNICAMP pela concessão da bolsa. Aos Moinhos Catarinense, Anaconda, Paulista, LCA Alimentos, Antoniazzi e Correcta, e à Bunge Alimentos pela doação das matérias-primas. 